\title{
GEEN SEKS, GEEN SKADEVERGOEDING
}

\section{$1 \quad$ Inleiding}

Daar kan nie langer ernstiger gevolge aan verlowingsverbreking geheg word as aan huweliksbeëindiging nie. Dit is die gevolgtrekking wat adjunkpresident Harms gemaak het in die saak Van Jaarsveld $v$ Bridges (ongerapporteerde saak no 344/09 2010 HHA ZASCA 76 van 27 Mei 2010). Wanneer 'n verlowing verbreek is, kon die benadeelde party die "skuldige" party dagvaar vir troubreuk en as troubreuk bewys is, kon daar ook 'n eis om skadevergoeding ingestel word. Alhoewel dit nie 'n vereiste is nie, word 'n huwelik gewoonlik deur 'n verlowingskontrak voorafgegaan. Hierdie kontrak is 'n kontrak sui generis (Sinclair The Law of Marriage (1996) 313-325). Die verlowing is ' $n$ kontrak om in die huwelik te tree en sodra die huwelik voltrek word, kom die kontrak tot 'n einde.

In die Romeinse reg kon die partye nie gedwing word om 'n verlowingskontrak te sluit nie, en as die verlowing verbreek word, kon geen skadevergoeding geëis word nie. In die Suid-Afrikaanse reg kan daar wel vandag beperkte skadevergoeding na die verbreking van 'n verlowingskontrak geëis word. Die hof sal in navolging van die Bridges-uitspraak slegs verspilde uitgawes aangegaan ten opsigte van die huwelik se voorbereidings in ag neem. Vroeër is die volgende in ag geneem by die bepaling van skadevergoeding; die geldelike verlies wat die eiser gely het, die finansiële posisie van die verweerder, die sosiale stand van die partye en die omvang van die eiseres se emosionele pyn (Radlof $v$ Ralph 1917 EDL 168 174; sien ook Guggenheim v Rosenbaum 219614 SA 21 (W); en Sepheri v Scanlan 20081 SA $322(\mathrm{~K})$ ).

Wanneer 'n huwelik egter deur egskeiding beëindig word, kan daar nie skadevergoeding weens kontrakbreuk geëis word nie. Hierdie realiteit is onlangs weer bevestig in $D \vee D$ (2007 ongerapporteer WPA, saaknommer 8422/2006; en sien ook Le Roux "Is 'n Huwelik 'n Kontrak?" 2010-02-24 Beeld).

In bogenoemde $D \vee D$ is bevestig dat 'n huwelik nie 'n kontrak is nie en derhalwe is die remedies vir kontrakbreuk nie tot die beskikking van die benadeelde party nie. Die gevolg hiervan is dat ongeag die feit dat seksuele gemeenskap 'n genieting van niemateriële aard van die huwelik is, kan 'n vrou (of man) nie regtens 'n eis om skadevergoeding teen haar man (of vrou) instel indien daar geen seks in die huwelik plaasvind nie. Dit kan wel bydra tot die bewys van onherstelbare verbrokkeling in die sin dat daar nie 'n normale consortium omnis vitae bestaan nie.

\section{Geskiedenis van die huwelik}

'n Huwelik is tradisioneel omskryf as die regtens erkende lewenslange vrywillige verbintenis tussen een man en een vrou tot uitsluiting van alle 
ander persone (Heaton Die Suid-Afrikaanse Familiereg (2010) 15). In die lig van die Civil Union Act 17 van 2006 en die beslissing in Minister of Home Affairs v Fourie (2006 1 SA 524 (CC)) is hierdie definisie egter uitgedien asook ongrondwetlik aangesien 'n huwelik tussen persone van dieselfde geslag nou ook moontlik is. Alhoewel die huwelik 'n vrywillige verbintenis is wat op consensus (wilsooreenstemming) gebaseer is, word algemeen erken dat die huwelik nie 'n kontrak is nie.

"Marriage is an agreement in that it is based on the consensus of the parties, but it is certainly not an ordinary contract in the sense of an agreement creating obligations. As has been pointed out by several writers, while it is true that marriage does give rise to obligations, such as the reciprocal duty of support, the primary goal of marriage is not the creation of obligations. Many of the normal principles of the law of contract do not apply to marriage ... Moreover many of the consequences of marriage cannot be expressed purely in terms of legal rights and duties" (XVI LAWSA re par 12).

In Ex parte $A B$ (1910 TS 1332 1338-1339) stel regter Wessels dit dat "a marriage is not an obligatio, and it does not fall under the category of contractual obligations". Hy haal regter Brett aan in 'n Engelse saak Morduant v Moncreiffe (48 LJ PD 49):

"Marriage is not as often popularly stated, a contract. If it were it could according to every principle of the laws of contracts be rescinded by mutual consent, but it cannot. There is a contract before marriage, which is a contract to marry, but marriage is the fulfilment of the contract which is then satisfied and ended, and there is no further contract."

In die Romeinse reg is 'n huwelik omskryf as die samevoeging van 'n man en 'n vrou en dit is 'n unieke gebruik eie aan die lewe: nuptiae autem sive matrimonium est viri et mulieris conjunctio, individuam consuetudinem vitae continens (Justinianus Inst 19 1). Die geldigheidsvereistes vir 'n huwelik was soos volg: die partye moes volgens die voorskrifte van die wet trou (secundum praecepta legum), die man moes puberteit bereik het (masculi quidem puberes) en vroue moes van troubare ouderdom gewees het (feminae autem viripotentes). Toestemming was 'n materiële vereiste vir die sluiting van 'n geldige huwelik (sien Jacobs 'n Ondersoek na die Regsbeskerming van die Vrou se Huwelikverhouding tydens die Klassieke Romeinse Reg (1997 verhandeling SA); en Sinclair 184). Dum tamen filiifamilias et consensum habeant parentum, quorum in potestate sunt ( $C 5$ 425 ). Die toestemming van die paterfamilias, sowel as die partye self was 'n vereiste; dus was dit toestemming wat die huwelik tot stand laat kom het: nuptias non concubinatus, sed consensus facit ( $D 501730$ ).

Volgens Sinclair herinner die vereistes vir die sluiting van 'n geldige Germaanse huwelik sterk aan die huweliksluiting onder inheemse SuidAfrikaanse stamme: die huwelik was 'n kontrak tussen die twee families eerder as tussen twee individue en die bruidegom het ' $n$ bedrag geld (pretium nuptiale) aan die bruid se vader oorgehandig (185-186). Laasgenoemde gebruik is vergelykbaar met die betaling van lobolo onder die inheemse Suid-Afrikaanse kulture. Die bruid word dan aan die bruidegom oorhandig en na die huweliksfees is die bruid na die bruidegom se huis geneem waar die huwelik bekragtig is deur gemeenskap. 
Gedurende die Middeleeue het huweliksluiting onder die jurisdiksie van die kerk geval en sodra ' $n$ huwelik finaal voltrek is deur gemeenskap, kon dit nie deur 'n mens ontbind word nie (Sinclair 188). Die Corpus luris Canonici het die Romeinse reg gevolg en bepaal dat 'n huwelik deur toestemming tot stand kom en nie deur gemeenskap nie ( $D 501730$ ).

Volgens die Kanonieke reg kan die Pous 'n huwelik wat nie deur seksuele gemeenskap voltrek is nie, ongeag die rede daarvoor, nietig verklaar. Die weiering om 'n huwelik seksueel te voltrek of die onvermoë om dit te doen, is ook gronde vir nietigverklaring.

"A marriage has been consummated when the spouses have performed between themselves in a human fashion a conjugal act which is suitable in itself for the procreation of offspring, to which marriage is ordered by its nature and by which the spouses become one flesh (http://www.vatican.va/ archive/ENG1104canons)."

De Groot (1583-1645) definieer 'n huwelik soos volg: "Huwelick ofte echt is een verzameling van man ende wijf tot een gemeen leven, medebrengende een wettelick gebruick van malkander lichaem" (Inleidinge 151 ). Die oogmerk van die huwelik was om mekaar se liggame te geniet; dus om gemeenskap te hê en indien een lid van die paartjie nie tot gemeenskap in staat is nie, moet hy of sy hom of haar nie in 'n huwelik begeef nie. "Dulle luiden, als geen vrije wille hebbende, ende mans ofte wijven die door aengeboren gebreck tot teelinge onbequaem zijn, mogen haer oock ten huwelick niet begeven" (Inleidinge 154 ).

Van der Keessel (1738-1818) wys daarop dat impotensie 'n grond vir nietigverklaring van ' $n$ huwelik is: "Qui vitio quod generationi obstat, perpetuo et insanabili laborant, illos nuptias valide inire non posset itidem notidem notissimum est" (Van der Keessel Praelectiones 15 69). Wanneer die vrou teen haar eggenoot se impotensie beswaar wou maak, moes sy drie jaar wag om dit te doen. Volgens Van der Keessel was dit nie nodig dat 'n huwelik deur gemeenskap finaal voltrek word vir die gewone gevolge van die huwelik, soos gemeenskap van goed, om in te tree nie (1 5 87). Egskeiding is erken in die Romeins-Hollandse reg en was op die skuldbeginsel gebaseer. Egskeidingsgronde was egbreuk en kwaadwillige verlating (Sinclair 192). Volgens Voet (1647-1713) was die posisie in Holland dat toestemming genoeg was om 'n geldige huwelik tot stand te laat kom en is geen verdere vereiste soos seksuele gemeenskap gestel nie (Commentarii ad Pandectas 232 93), maar volgens die Frisiese reg, anders as die Hollandse reg, en die reg van Utrecht moes 'n huwelik ook deur gemeenskap finaal voltrek word om geldig te wees. Voet behandel verder die gevalle wanneer 'n huwelik nietig verklaar kon word, onder andere; bloedskande, die afwesigheid van toestemming en gevalle van impotensie wat voor die huwelik bestaan het (24 2 15). In sodanige gevalle moes die impotensie van die begin van die huwelik af bestaan het en vir drie jaar aangehou het en ongeneeslik wees.

Huber (1636-1694), skrywer van Frisiese reg, dui aan dat toestemming alleen nie voldoende was nie en dat ' $n$ huwelik finaal voltrek moet word deur gemeenskap en dat die party wat onwillig daartoe is, gedwing kan word deur gevangenissetting en opsluiting (Huber Heedensdaegse Rechtgeleertheyt 1 
5 9). Hy skryf verder dat impotensie nie 'n grond vir egskeiding is nie, maar eerder ' $n$ bewys is dat die huwelik van die begin af nietig was (1 66 ).

\section{Die Huwelikswet 25 van 1961}

Volgens die Suid-Afrikaanse Huwelikswet 25 van 1961 moet aan al die geldigheidsvereistes naamlik: handelingsbevoegdheid, wilsooreenstemming, geoorloofdheid en formaliteite voldoen word vir 'n huwelik om geldig te wees. Die omgekeerde is dus dat as daar aan al die vereistes voldoen word, daar ' $n$ geldige huwelik is. In $D v D$ is aan al die statutêre geldigheidvereistes voldoen. Mnr D en mev D was dus wettiglik getroud. In die vyf jaar wat die huwelik geduur het, het die egpaar egter nooit seksuele omgang gehad nie en is die huwelik hoewel wettig, dus nooit voltrek nie.

Die man, mnr $D$, het mev $D$ vir 'n egskeiding gedagvaar. Mev $D$ het ' $n$ teeneis gebaseer op kontrakbreuk ingestel en skadevergoeding gevorder. Omdat aan al die gedigheidsvereistes van 'n huwelik voldoen is, kon die huwelik nie per se nietig verklaar word nie. Die feit dat geen seksuele gemeenskap tussen die paar plaasgevind het nie, is nie 'n rede vir die nietigverklaring van die huwelik nie, hoewel dit daarop dui dat die consortium omnis vitae, indien dit hoegenaamd tot stand gekom het, verbreek is. Die feit dat die consortium verbreek is, is 'n aanduiding dat die huwelik onherstelbaar verbrokkel het (Heaton 44).

Die hof kan 'n huwelik slegs nietig verklaar op grond daarvan dat 'n formele of materiële vereiste vir die totstandkoming van 'n siviele huwelik nie nagekom is nie - seksuele omgang as sodanig, is nie 'n vereiste nie (Heaton 35; en Sinclair 402). Die huwelik kan egter vernietigbaar wees op grond van impotensie van mnr D. 'n Vernietigbare huwelik is 'n huwelik waarin daar voor of by huweliksluiting gronde aanwesig was uit hoofde waarvan die hof versoek kan word om die huwelik te ontbind (Heaton 36 ).

Mnr D kan na bewering nie normale seksuele omgang hê nie, hoewel die woord "impotensie" nie in hofuitspraak gebruik word nie. Hy kan dus ook homoseksueel wees of selfs owerspelig lewe. Sou hy egter impotent wees, met ander woorde, nie die vermoë hê om aan die geslagsdaad deel te neem nie, kan enige van die twee huwelikspartye die hof nader vir 'n ontbinding van die huwelik. Volgens Sinclair (390) is die toets vir impotensie die onmoontlikheid van gemeenskap. Dit maak nie saak of dit fisiese of psigiese impotensie is nie. Dit is belangrik dat die impotensie permanent moet wees; indien daar ' $\mathrm{n}$ geringe kans is dat dit genees kan word met behandeling, moet die verweerder die kans gegun word om te probeer.

Die voorvereiste vir die ontbinding van die huwelik is egter dat die man in die geval reeds voor huweliksluiting impotent was en nog steeds is en dat mev $D$ tydens die huweliksluiting onbewus van die impotensie was. Indien sy bewus was van die impotensie of dit gekondoneer het, sal sy nie met 'n aansoek om tersydestelling van die huwelik slaag nie. Om eenvoudig te weier om gemeenskap te hê, is nie 'n grond vir nietigverklaring nie (Sinclair 391). Dieselfde geld wanneer een van die gades impotent word na huweliksluiting. In laasgenoemde geval mag dit tot die onherstelbare verbrokkeling van die huwelik lei, wat 'n grond vir egskeiding is. 
In vroeëre regspraak het min of meer dieselfde probleem na vore gekom; in $W v W(19594$ SA $183(\mathrm{~K}))$ het die vrou ' $n$ aksie om egskeiding ingestel. Die man het ' $n$ teeneis geliasseer en aangevoer dat hy ten tyde van die huweliksluiting impotent was en nog steeds is. Hy het verder beweer dat hy nie ten tyde van huweliksluiting bewus was van sy impotensie nie. Nietigverklaring van die huwelik is toegelaat.

In Smith v Smith (1961 3 SA 359 (SR)) word selfs verder gegaan deurdat die regter in die uitspraak gesê het as die eiser geweet het van die impotensie tydens huweliksluiting, maar op redelike gronde geglo het dat dit sou herstel, hy nie verhinder kan word om 'n nietigverklaring van die huwelik te verkry nie.

In Joshua $v$ Joshua (1961 1 SA $455(\mathrm{GW})$ ) is gestel dat dit onbelangrik is of die impotensie aan fisiese of sielkundige faktore te wyte is, maar as ' $n$ vrou met 'n ou man van 85 jaar trou, behoort sy te weet dat hy moontlik impotent kan wees en dus sal 'n nietigverklaring nie toegestaan kan word nie.

Indien daar sprake van impotensie is, is die huwelik vernietigbaar. ' $n$ Vernietigbare huwelik bly geldig en het al die normale regsgevolge van 'n geldige huwelik totdat dit deur 'n hofbevel tersyde gestel word (Heaton 39). Indien die huwelik ter syde gestel word, geld die hofbevel terugwerkend. Dit beteken die partye word weer in dieselfde posisie gestel as waarin hulle sou gewees het as die huwelik nooit aangegaan is nie.

\section{$4 \quad$ Eis om skadevergoeding}

Mev $D$ het nog nooit in die vyf jaar van haar huwelik seksuele omgang met haar man gehad nie. Sy sou dus moet bewys dat die probleem by haar man aanwesig was met en na huweliksluiting én dat sy onbewus was daarvan. Indien sy dit kon doen, kon sy om 'n nietigverklaring by die hof aansoek doen en kon sy derhalwe skadevergoeding eis om sodoende in dieselfde posisie te wees as waarin sy was voor die huweliksluiting. Sy het R180 000 as skadevergoeding vir die verbreking van die "huwelikskontrak", soos volg saamgestel, geëis:

(i) geld wat vermors is met die huwelikseremonie - R30 000.00;

(ii) verlies aan finansiële voordele van die huwelik - R100 000.00.

Die gades het onder andere ooreengekom dat die vrou haar werk sou bedank een maand voor die huwelik sou plaasvind. Dit het sy wel gedoen. Verder het sy ook R50 000 geëis vir sogenaamde "persoonlike skade" oftewel troosgeld omdat haar waardigheid en reputasie aangetas is.

Indien die vrou in die onderhawige saak nie impotensie kan bewys nie, of dit blyk dat sy daarvan bewus was, is daar wel 'n geldige huwelik en kan sy slegs om 'n egskeiding aansoek doen gebaseer op die duursame verbrokkeling van die huwelik.

Die onderskeid tussen die nietigverklaring van 'n vernietigbare huwelik en 'n egskeiding onderlê ook wesenlik verskillende gevolge. Sedert die inwerkingtreding van skuldlose egskeiding in die Suid-Afrikaansreg, kom minder sake voor waar die vordering vir nietigverklaring is (Sinclair 413). ' $n$ Huwelik is vernietigbaar op grond van omstandighede wat reeds voor of ten 
tyde van huweliksluiting aanwesig was; 'n egskeiding daarenteen word verleen op grond van omstandighede wat gedurende die huwelik onstaan het. Die Wet op Egskeiding is nie op die nietigverklaring van 'n vernietigbare huwelik van toepassing nie. Wanneer die huwelik nietig verklaar word, word die partye slegs gestel in die posisie wat hulle was voor huweliksluiting, geen skadevergoeding of onderhoudseise kan ingestel word nie. Met 'n egskeiding kan die afhanklike party wel 'n onderhoudseis instel indien hy of sy kan bewys dat hy of sy behoefte aan onderhoud het.

Artikel 4(1) van die Wet op Egskeiding 70 van 1979 bepaal dat 'n hof 'n egskeidingsbevel op grond van die onherstelbare verbrokkeling van 'n huwelik slegs verleen indien hy oortuig is dat die huweliksverhouding tussen die partye by die huwelik so 'n toestand van verbrokkeling bereik het, dat daar geen redelike vooruitsig op die herstel van 'n normale huweliksverhouding tussen hulle bestaan nie. Indien die egskeiding toegestaan word, tree artikels 6 tot 10 van die wet in werking wat betrekking het op die vermoënsregtelike gevolge van 'n egskeiding. Hierdie artikels bepaal hoe die boedel verdeel moet word, afhangende van hoe die partye getroud is. Geen melding word van skadevergoeding gemaak nie. Mev D sal dus net geregtig wees op dit wat haar toekom volgens hul huweliksgoederebedeling.

\section{$5 \quad$ Gevolgtrekking}

Die indruk is dus in die verlede geskep dat 'n persoon volgens die SuidAfrikaanse reg beter daaraan toe is wanneer 'n verlowing verbreek word, as wanneer 'n huwelik beëindig word, aangesien 'n verlowing 'n kontrak is en die benadeelde party dus skadevergoeding kan eis terwyl 'n huwelik nie 'n kontrak is nie. Hierdie siening is egter omver gewerp in die appèlsaak Van Jaarsveld $v$ Bridges. Me Bridges het in die verhoorhof R10 000 genoegdoening geëis vir naamskending en R172 413 skadevergoeding omdat Van Jaarsveld hul verlowing beëindig het. Haar eis was suksesvol in die verhoorhof, maar op appèl merk adjunk-regter-president Harms op dat daar ' $n$ verpligting op die howe is om die gemenereg uit te brei (iets wat Davis $R$ nie in Sephiri v Scanlan 20081 SA 332 (K) wou doen nie) terwyl die belang van geregtigheid en menseregte ook in ag geneem moet word. Syns insiens het die tyd aangebreek om met nuwe oë na die verbreking van 'n verlowing te kyk, aangesien die huidige stand van sake nie meer die mores van ons tyd reflekteer nie. 'n Verlowingsverbreking kan aanleiding gee tot twee tipes vorderinge: die een gebaseer op naamskending en die ander op kontrakbreuk. Die appèlregter is egter van mening dat dit onlogies is om langer ernstiger gevolge aan 'n verlowingsverbreking te heg as aan huweliksbeëindiging: "it is difficult to justify the commercialization of an engagement in view of the fact that a marriage does not give rise to a commercial or rigidly contractual relationship".

Die enigste werklike skade wat volgens die appèlhof geëis kan word na die verbreking van 'n verlowing, is die verspilde uitgawes wat aangegaan is ten opsigte van die huwelik se voorbereidings. Dit is uitgawes wat vloei uit die ooreenkoms tussen die partye en nie vanweë die kontrak om te trou nie. Die appèl is met koste gehandhaaf en me Bridges is met leë hande uitgestuur, want sy kon nie voldoen aan die vereiste vir hetsy die troosgeld of die skadevergoeding wat sy gevorder het nie. Met dié bevinding het die 
appèlregters die geykte reg in verband met troubreukeise aansienlik gewysig sodat dit in die toekoms nie maklik toegestaan sal word nie. Bridges het haar op die konstitusionele hof beroep om die appèlregters se uitspraak te hersien en ter syde te stel. Tien regters van die konstitusionle hof het egter haar aansoek verwerp omdat daar geen vooruitsig op sukses was nie.

Dit is 'n stap in die regte rigting. Indien die howe hierdie uitspraak in die toekoms navolg, sal 'n persoon wie se verlowing verbreek word; dus nie meer in 'n beter posisie wees as die persoon wat skei nie. Dit lyk dus of die howe ten gunste is van 'n "geen skuld"-benadering ten opsigte van die verbreking van 'n verlowing, net soos egskeiding tans ook op 'n "geen skuld"-benadering gebaseer is. Die vraag kan egter nou tereg gevra word of die huwelik nie ook in 'n nuwe lig beskou moet word inaggenome die mores van ons dag nie. Wanneer paartjies saamwoon, word hulle saamwoonverhouding uit en uit kontraktueel gereël, moet die huwelik dan nie ook maar as 'n kontrak gesien word nie? As mens appèlregter Harms se pariteitsbeginsel aanwend om die bespreekte twee sake se uitkomste toe te pas, lyk dit asof me Bridges benadeel is, maar sonder dat mev $\mathrm{D}$ bevoordeel is. Moes mev D se skadevergoedingseis nie geslaag het nie? Was dit nie dalk die bedoeling van haar regspan om so ' $n$ eis na die howe te bring in die hoop dat die howe 'n huwelik as 'n kontrak sou beskou nie?

Wanneer immateriële aspekte van die consortium, soos seksuele omgang in 'n huwelik verbreek word, is daar geen geldelike vergoeding vir die benadeelde party nie. Onderhoud na egskeiding is van finansiële aard en daarom kan ' $n$ benadeelde party ' $n$ onderhoudeis instel as hy of sy onderhoudsbehoeftig is. In Bruwer $v$ Joubert (1966 3 SA 334 (A)) is skadevergoeding vir "ideële" skade, verlies aan liefde en geestelike steun, toegeken, maar in hierdie saak het dit oor owerspel gehandel (337D-E) en nie 'n gebrek aan seksuele omgang nie.

Sedert die vroegste tye was een van die voordele van 'n huwelik die genieting van mekaar se liggame, ofte wel geslagsgemeenskap, hoewel dit nie meer soos in die middeleeue vandag ' $n$ vereiste is dat ' $n$ huwelik deur gemeenskap voltrek word nie. Dus, alhoewel dit een van die voordele van 'n huwelik is om seks te hê, is dit nie 'n materiële/finansiële voordeel nie en derhalwe word daar geen bedrag aan gekoppel soos mev $D$ wou gehad het die hof moes doen nie; sy bly dus sonder seks en sonder skadevergoeding!

Magda Slabbert

en

Carina van der Westhuizen Universiteit van Suid-Afrika (UNISA) 